\title{
The Use of Digital Technologies in Pedagogical Education in Kazakhstan: Problem State
}

\author{
Ussenova G. S..$^{1, *}$, Maigeldiyeva S. M. ${ }^{1}$, Fominykh N. Iu. ${ }^{2}$, Tleubay S. ${ }^{1}$, Meirbekova G. P. ${ }^{3}$ \\ ${ }^{1}$ Korkyt Ata Kyzylorda State University, Kazakhstan \\ ${ }^{2}$ Plekhanov Russian University of Economics, Russia \\ ${ }^{3}$ Akhmet Yassawi International Kazakh-Turkish University, Kazakhstan
}

Received September 25, 2020; Revised November 23, 2020; Accepted December 4, 2020

\section{Cite This Paper in the following Citation Styles}

(a): [1] Ussenova G.S., Maigeldiyeva S.M., Fominykh N.Iu., Tleubay S., Meirbekova G.P. , "The Use of Digital Technologies in Pedagogical Education in Kazakhstan: Problem State," Universal Journal of Educational Research, Vol. 8, No. 12A, pp. 7748 - 7754, 2020. DOI: 10.13189/ujer.2020.082562.

(b): Ussenova G.S., Maigeldiyeva S.M., Fominykh N.Iu., Tleubay S., Meirbekova G.P. (2020). The Use of Digital Technologies in Pedagogical Education in Kazakhstan: Problem State. Universal Journal of Educational Research, 8(12A), 7748 - 7754. DOI: 10.13189/ujer.2020.082562.

Copyright $\bigcirc 2020$ by authors, all rights reserved. Authors agree that this article remains permanently open access under the terms of the Creative Commons Attribution License 4.0 International License

\begin{abstract}
Digital society, the digital economy, has become true and in turn, generates unique challenges due to the rapid pace of growth of information and communication technology. Digital capabilities and skills are necessary to achieve professional achievement and the personal growth of any person in this world. In terms of reform and modernisation of the global educational system, digitalisation of education is one important trend. Digitisation means the transformation into the digital language of all forms of information (text, sound, visuals, video and other data from different sources). When debating digitalisation, different experts and scholars view the transition from education into the digital phase as a turning point in education history. The UK is supposed to be the first in the world to add compulsory IT and software in 2015 to the schoolchildren's curriculum at age 5-16. The article deals with a very actual problem of digitalization of pedagogical education on the basis of a combination of environmental, competence-based and activity-based approaches. The results of the survey of Pedagogical Faculty instructors and students of Korkyt Ata Kyzylorda State University are presented in the article. The results show that although both groups of respondents are aware of using digital technologies in education, they do not develop systematic use of all their (technologies) opportunities. According to these results, the article states the need for developing a model for the development of cognitive independence of future educators based on the use of digital technologies.
\end{abstract}

Keywords Digital Technologies in Education, Pedagogical Education, Research Results, Electronic Educational Environment, Environmental Approach, Competence-based Approach, Activity-based Approach

\section{Introduction}

Russia today is facing the challenge of introducing and maintaining creative systems at all social production levels and stages. Implemented technologies are inefficient, creative thinking in the process of designing and enhancing an innovative product is not profitable; they become redundant. According to this study, the experts agreed that there was no management staff in the International Economic Forum who was capable of carrying out innovation projects and that one of the main reasons for this situation was the lack of people who could do creative work. The question arises as to how to achieve the objectives of product strategy design, growth and development, and the achievement of national strategic objectives on its basis. Among the conventional means, which include finance, scientific knowledge, natural resources, development basis, and so on, the main means are human capital both at the national and regional level and at the level of economic entities. This resource is universal and will allow Russia to develop and use other resources competently and eventually become a world 
intellectual leader [Dorofeeva \& Nyurenberger, 2019; Karakozov \& Ryzhova, 2019; Machekhina, 2017; Makarova et al., 2018; Mertala, 2020; Plotnikova, 2019].

Despite Russian confidence in almost all countries of the world, the number of university students per 10,000 people today has fallen substantially. University professors complain that school graduates are of low quality in training. Employers, on the other hand, not only question the standard of the preparation of diplomats but also have to complete their studies in special programs and spend tens of thousands of dollars on a new young specialist.

In sociological surveys conducted in 2018 in Russia, the majority not called capital, not raw materials and even not technology but a shortage of skilled personnel, particularly skilled economists and managers, in response to a question: lack of resources hinders economic growth [Arkhipova \& Kuchmaeva, 2018; Medvedev, 2018; Popkova \& Sergi, 2020].

In other words, a paradoxical situation occurs in the country in which the quantity of supplies of practitioners in socio-economic disciplines exceeds their demand and the demand for qualified managers and experts in the fields of economic and judicial matters exceeds their availability. In this case, only the mobilization and concentration of all country capital to solve tasks should become a national policy [Popkova \& Sergi, 2020]. In addition to requiring a sufficient number of leading people to adapt to modern technical, manufacturing, economic and social reality, well-trained specialists are also needed in the priority areas of growth for the country $\mathrm{s}$ socio-economic development.

Specific new priorities and strategies, new internal tools for the nation (including experience), work shortages and structure, demographic threats and others challenges to the outside world lead to the broad use of digital technology in education. This required the conceptual response of the leaders, public administration and private enterprises of the country, leading to the creation of a number of policy papers, in particular, the strategy "Russian Digital Economy". This approach can and must be adopted as a balanced symbiosis of the modernization of the conventional Russian economy sectors (oil and gas, raw materials, agriculture, transport, etc.) as well as an accelerated growth of high-tech manufacturing and creative goods in all sectors of the national economy (as national product policies) [Gaddy \& Ickes, 2002; Hache et al., 2019; Laurila, 2003; Sagers et al., 1995].

We need to start with education, a spiritual and moral education system focused on patriotic and conservative values. For training and creative growth, an education system needs to be built that helps to instil the knowledge and personal characteristics needed for developing an innovative economy in people. Not only university students and schools, but also schoolchildren and also pre-school children must be paid attention because today they will have to continue to modernize the world.
Moreover, it must be borne in mind that children are predominantly raised in the home, and so mood and the desire for change in the older generation must be created.

Education digitalization includes different qualitative aspects, ranging from organizational problems, technical resources, pedagogical approaches and internationalization influences through providing online programs that are versatile [Kesici \& Tunç, 2018; Sá \& Serpa, 2020]. In addition, it allows for administrative solutions, data protection systems, cheating detection systems, plagiarism, data storage, library facilities and a range of learning tools, as well as opportunities for greater communication across campuses. In addition, the digitization of those involved still needs appropriate skills. Most scholars researched digitalization as either external or internal processes. The most important results are the influences of foreign systems, mostly guided either by government initiatives or multinational initiatives, by global institutional strategies.

Governments can influence the way institutions of higher education to manage technology, for example, through funding, quality requirements, and the creation of a suitable technological infrastructure. Via policies, program changes and reorganization, higher education institutions will fulfil these overall policy requirements. Previous studies indicate that the overall solutions for digitalisation in higher education and education are either lacking, scarce or incomplete.

The results show that while most universities have online course policies and strategies, most lack policies to help, create and evaluate courses. Furthermore, in contrast to e-learning/online learning activities carried out by individual departments and individual academics, the development of overall strategies within higher education institutions for e-learning and development continues to be new areas.

Most of the higher education institutions provide technical assistance to academic personnel in a department, organization or unit. These units are responsible for the management of the education technology invested by the institutions and for directing academic employees' implementation of the technology. Furthermore, the people who work in these fields most often have various skills such as pedagogical skills and technical skills.

In short, previous studies have shown that while there are some exceptions to individual advocates, who support education technology among academics, they have only a small effect on the overall approaches to teaching and learning digitalisation. The most important results from the literature review were that external mechanisms that had only minimal effect on digitalisation in higher education institutions, here called top-down interventions by policymakers and institutional bodies. In addition, most internal digitalization processes may be recognized as top-down programs and most likely controlled by government rather than academic personnel. 
The relevance and significance of the process of digitalization of professional education and training are caused by the global processes of transition to the digital economy and digital society. Especially it concerns professional education of teachers who are standing at the front of any social development. Speaking about the digitalization of education, we should think about three main points here:

- first of all, it is forming of the educational environment as a set of digital learning tools, online courses, electronic educational resources and their possible combinations;

- secondly, it is full modernization of the educational process with its traditional organizational forms and means of learning and teaching, including the deep transformation of the main methodological and didactic basis;

- and, thirdly, it is a necessity to provide prospective educators with the possibility to live in a digital society and work in the reality of the digital economy.

These points, in our opinion, are the priority tasks on the way to use of digital technologies in pedagogical education and the main idea of this article is to describe some basic aspects of the problem, as well as to study the readiness of prospective Kazakhstan educators for using digital technologies in their professional training and future professional activity.

\section{Materials and Methods}

In order to conduct a holistic, objective and productive scientific research we relied on a wise combination of foundations of methodological approaches such as environmental [Eliseeva et al., 2016; Marusynets et al., 2019; Zubkova et al., 2019], competency-based [Alijev et al., 2020; Fahrutdinova et al., 2014; Kunanbayeva, 2016; Orekhova et al., 2019; Romanovtseva, 2016], and activity-based [Ananiev, 2008; Bakhru \& Mehta, 2020; Kanchana et al., 2019; Prapinpongsakorn, 2020; Suydam \& Higgins, 1977]. An obvious connection between the above-mentioned aspects with these methodological approaches is observed.

Thus, the environmental approach is used to design the electronic educational environment and define its components needed to meet all possible educational needs of students. The main advantage of using an environmental approach is a guaranteed right of the student to participate in the design of the educational environment by the selective perception of environmental components and interaction with them. This environment should be rich in diverse electronic educational resources, almost unlimited in terms of content, methods and organizational forms.

We define the electronic educational environment as a set of certain conditions and rich opportunities for training, comprehensive development, socialization, and education for everyone.

These components of the electronic educational environment, in our opinion, are:

- methodological block describing approaches, models, methods and scenarios of work in the digital educational environment;

- human resources block, which implies using digital technologies by teachers and students in their professional activities;

- informational block, providing teachers and students with access to a variety of educational content which we call electronic educational resources.

Among electronic educational resources, we highlight e-books designed on the basis of different learning/teaching tools and services, massive open online courses (MOOC), video and audio educational materials.

The main principle which unites all these components we consider to be student-centric as it is presented in Figure 1.

The student-centric principle means that all the components of the electronic educational environment are designed to satisfy the educational needs of students, develop their aptitudes and talents, meet the age characteristics and personal interests of the students. In addition, this implies maximum consideration of the natural abilities of every student's personality, providing the opportunity to build their own learning trajectory for a complete disclosure of abilities based on mutual learning, self-learning, constructing their own system of knowledge about the surrounding reality and obtaining their own learning experience.

Thus, the electronic educational environment should then provide an opportunity for every user not only to learn efficiently, but also to develop the initial personal potential, encourage the need for further self-knowledge, creative self-development, and contribute to career planning and professional development.

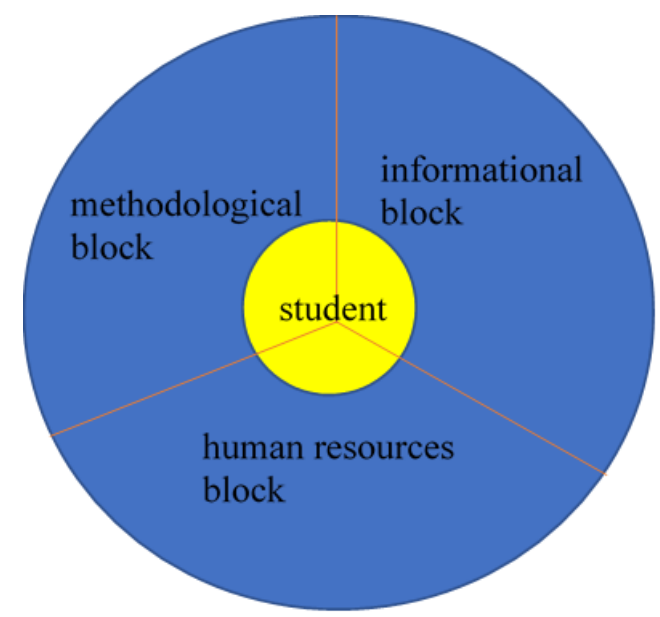

Figure 1. The structure of the electronic educational environment (student-centric principle) 
Secondly, considering the most significant achievements of adherents of the activity-based approach [Ananiev, 2008], the most effective and progressive for educational system digital technologies were defined. We consider them to be Big Data, Deep Learning, Augmented Reality (AR), Blockchain, Artificial Intelligence (AI), ChatBot, and Cloud technologies. Let us characterize each of them briefly.

The ability to work with Big Data allows using the potential of AI to support the educational, scientific and creative activities of students. Big Data allows creating a system of personalized monitoring of learning success and tracks the dynamics of the personal development of every student.

Deep learning is of particular interest in connection with the development of virtual Augmented Reality machines that allow simulating technological processes in virtual space. This technology provides students with the opportunity to see, feel and evaluate their actions in a professional environment.

As for Artificial Intelligence itself, it is a base for designing individual educational trajectories, adaptive learning systems which are adjusted to the individual needs of every concrete student, self-learning e-consultants, and organizing training according to individual curriculums.

Chat Bot technology is used in education to organize instant, meaningful feedback to everyone in the process of distance learning. Chat Bot technology gives an automatic reply to some typical questions of learners and makes the process of communication easier, more effective and much faster. This technology is mostly based on basic principles of AI, using Artificial Intelligence algorithms that allow simulating a conversation with a live person.

Cloud technologies make it possible not only to combine information resources and simplify their use. Blockchain technology, which has become famous in connection with the spread of cryptocurrencies, is actively beginning to be used in foreign universities in the preparation of final qualifying works.

This allows teachers and employers to track the progress of a student in performing a task in an open information environment, and to assess their prospective opportunities for employment in the company.

Blockchain in education is an open self-developing system, where a certain goal acts as a parameter of order (ensuring high-quality training of a specialist, project implementation, personal development, their cognitive independence, etc.), for which an active dialogical interaction of all participants of the educational process is implemented using the cloud information space, it allows to ensure the achievement of the set goal and methods of forming the personal and professional success of the student in the educational process. The organization of educational activities of students through blockchain technology encourages activity and independence in mastering the values of culture and achieving professionalism.

And at last, on the basis of competence-based approach, taking into account some modern researches [Alkhodary et al., 2020; Levine \& Patrick, 2019; Safuanov et al., 2019; Sullivan \& Downey, 2015], the set of digital competences of an educator was grounded:

- general computer literacy (search engine, word processing, basic hardware and software skills);

- pedagogical design skills (ability to design electronic educational resources, plan the lesson with their usage);

- planning and self-organization skills;

- analytical skills (ability to analyze information, problem-solving, ability to choose the necessary tools to solve certain professional and personal tasks);

- social media skills (ability to communicate with online communities, develop the net of own professional contacts);

- creativity skills (possibility to take part

- teamwork skills (ability to work in professional societies and groups, organize students' teamwork).

Here we should state that the other professional competences and personal skills of an educator are dramatically changed under the pressure of digitalization. For example, a traditional educator's competence to develop new educational programs, curriculums and learning tolls is transformed now into the ability to develop short-terms professional programs oriented on developing some limited sets of skills needed at this exact time. It is caused by the rapid change of technologies and the need to retrain.

\section{Results and Discussion}

In addition to this theoretical research, some practical surveys of the abovementioned aspects were conducted as well. Firstly, we analyzed the electronic educational environment of Korkyt Ata Kyzylorda State University. The analysis results demonstrated that a lot of electronic materials are used in the educational process, but in most cases, they are training materials converted into PDF format without using video, audio, etc. and other possibilities of digital technologies that were mentioned above. This means that the informational block of the electronic educational environment needs to be developed and filled with high-quality learning/teaching materials based on digital technologies authored by instructors of Korkyt Ata Kyzylorda State University.

In order to study the state of readiness of prospective Kazakhstan educators for using digital technologies in their professional training and future professional activity, the survey was conducted. In the survey, 172 students and 47 instructors of Pedagogy Faculty of Korkyt Ata 
Kyzylorda State University took part. The questions of the survey were aimed at clarifying three main aspects of the problem under study, which are:

- educational environment of the University (the number, quality and effectiveness of digital learning tools, online courses, electronic educational resources instructors/students use to teach/study);

- theoretical knowledge about digital technologies and understanding the essence of using them in education (name digital technologies that can be used in education, etc.);

- some practical skills of using digital technologies to teach/study (the aim of using digital technologies; an example of your favourite site and how you use it).

The survey included 16 questions that were almost identical for both groups of respondents (students and instructors) and was conducted online in the service Quia, and the access can be obtained: http://www.quia.com/sv/1097158.html (survey for instructors) and http://www.quia.com/sv/1097159.html (survey for students).

Thus, according to the results of the survey, $95 \%$ of University instructors have experience in using digital technologies in their professional activity, but further research revealed fragmentary knowledge in the field of digital technologies and ways to use them since only $33 \%$ of respondents were able to give examples of using services from the proposed list (for what purpose, during a classroom session or in the process of independent work, improving their own skills, private classes). In addition, only $25 \%$ of teachers themselves were able to provide examples of specific services and sites (not listed in the questionnaire) that respondents use in teaching.

As for the saturation of the electronic educational environment, $72 \%$ of teachers do not have their own websites, and $76 \%$ of respondents do not have any experience in designing electronic educational resources. At the same time, $12.5 \%$ of teachers indicated that they are developers of mass open online courses. However, they could not provide the names of these courses and the names of the platforms on which they are distributed. Such research results indicate not only the fragmentary knowledge of teachers about the use of digital technologies but also the insufficient content of the electronic educational environment with electronic educational resources, as well as the need to organize special work on the development of the personnel component of the electronic educational environment.

Analyzing the results of a survey of Korkyt Ata Kyzylorda State University Pedagogy Faculty instructors, it should be stated that they feel quite confident while using digital technologies in their professional activity, as instructors assessed their own level of digital technology proficiency as it is shown in Figure 2 (the majority (50\%) of instructors put themselves on a good level which is four digitally).
The goals for teachers to use digital technologies were ranked as follows:

- first of all, instructors prefer to use digital technologies for distance learning;

- this is followed by classroom sessions with using technologies;

- then instructors put improving their own skills on the basis of using digital technologies;

and just the last position in this ranking is given to autonomous students' work while leading research in the field of pedagogy and psychology has proven that technology has a huge potential for the development of the cognitive activity, independent learning, self-development and self-study.

Instructors' level of digital technology proficiency in professional activity

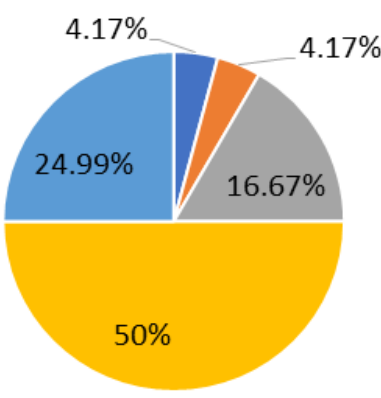

$=1-2 \quad 3=4-5$

Figure 2. The level of digital technology proficiency in professional activities (according to instructors' own opinion)

In contrary to these ranking results, it is commonly known that digital technologies have great potential for developing exactly students learning autonomy, as digital technologies allow:

- actively participate in the process of cognition of an object, process or phenomenon, better understand its nature, independently changing both its parameters and conditions of functioning;

- Search for the necessary information that can have a positive impact on cognitive independence and thus contribute to the rapid assimilation of the material;

- objectively identify the level of material understanding, which is very important in the learning process.

Such survey results make it necessary to develop a special model of prospective educator's cognitive independence development on the basis of digital technologies.

Let us look at the details of the results of the students' survey as well. Thus, students (prospective educators) use digital technologies and their opportunities in the educational process, and they raked the purpose of using them (technologies) in this way:

- firstly, prospective teachers prefer using the Internet to search for information; 
- secondly, technologies are used for machine translating and getting vocabulary (dictionary) help;

- thirdly, students (prospective educators) use digital technologies to search for films and books.

Such results prove that both students and instructors do not use all the potential opportunities of digital technologies to learn/teach more efficiently.

What is more, both groups of respondents have an incomplete understanding of the diversity of digital technologies and the opportunities they open for both the educators and the students. Thus, a list of 31 different educational services was offered in the survey. The list was followed by the question: "Tick the services you use to teach/study". Both respondents' groups reported just some Internet sites with ready educational decisions to be effective in the learning process, but they do not create their own learning/teaching materials on the basis of different services. In addition, $8.89 \%$ of respondents reported that they don't use any services at all. The results of both groups of respondents (students and instructors) are summarized in Table 1.

Such results of the survey prove the necessity to change methods and organizational learning forms, as digital technologies give opportunities to present learning/teaching materials in a variety of combinations, which lead to the disappearance of passive forms of working with information, which, in turn, leads to the need to develop new methods, technics, activities and forms of learning/teaching. Consequently, the methodological block of electronic educational environment should be developed (see Figure 1).

Table 1. Summarized results of the survey

\begin{tabular}{|c|c|c|c|}
\hline Service & $\begin{array}{c}\text { Number } \\
\text { of users }\end{array}$ & Service & $\begin{array}{c}\text { Number } \\
\text { of users }\end{array}$ \\
\hline Flikr & $8.89 \%$ & Respondus & $0.00 \%$ \\
\hline Quia & $0.00 \%$ & Podcast & $4.44 \%$ \\
\hline Youtube & $75.56 \%$ & Glogster & $0.00 \%$ \\
\hline Blogger & $4.44 \%$ & Google Translate & $60.00 \%$ \\
\hline Webquest & $2.22 \%$ & Prezi & $31.11 \%$ \\
\hline Google sites & $42.22 \%$ & Slide Rocket & $2.22 \%$ \\
\hline Wiki & $17.78 \%$ & Voice thread & $2.22 \%$ \\
\hline Slideshare & $6.67 \%$ & Facebook & $35.56 \%$ \\
\hline Community & $4.44 \%$ & Blabberize & $0.00 \%$ \\
\hline Walk & $0.00 \%$ & Mindomo & $2.22 \%$ \\
\hline Delicious & $4.44 \%$ & ESL video & $2.22 \%$ \\
\hline Essay Punch & $0.00 \%$ & Skype & $48.89 \%$ \\
\hline Writing Fun & $0.00 \%$ & Padlet & $6.67 \%$ \\
\hline Dvolver & $0.00 \%$ & Tagxedo & $2.22 \%$ \\
\hline Jupiter Grade & $0.00 \%$ & Wordle & $0.00 \%$ \\
\hline Nicenet & $0.00 \%$ & I don't use any & $8.89 \%$ \\
\hline Moodle & services & \\
\hline
\end{tabular}

This means that human resource block as an integral part of electronic educational environment (see Figure 1) should be developed by organizing special trainings on pedagogical design for University instructors and students.

\section{Conclusion}

The effect of digitalization on university education is clear. Graduates from the university need new skills to live, learn and work in digital society. The University of Basel aims to improve the respective skills of its students, teachers and staff in all related aspects with its strategic initiative "Digital Literacies".

To conclude, as the results of our pilot study have shown, the following aspects of the use of digital technologies in the education system of the Republic of Kazakhstan are relevant today and require the organization of special research and experimental work.

First of all, it is development of design models for the electronic educational environment, saturation of this environment with electronic educational resources, in particular, mass open online courses.

While it is well known that technology provides opportunities for independent work, self-development, self-improvement, self-education, both students and teachers do not use technology enough for this purpose. Respectively, for the second, we believe it is necessary to develop, implement in the educational process and test the effectiveness of a model for the development of cognitive independence of future educators based on the use of digital technologies.

And at last, thirdly, it is urgently needed to organize special work on developing educators' digital skills, which include abilities of efficient usage of digital technologies in the educational process.

\section{REFERENCES}

[1] Alijev, R., Chehlova, Z., Kevisa, I., \& Chehlov, M. (2020). The Civic Self-Consciousness Of Contemporary Secondary School Students In The Aspect Of The Humanistic Paradigm Of Education. Proceedings of the International Scientific Conference. Volume III, 43, 52.

[2] Alkhodary, M. A., Farah, R. I., \& Ghobashy, A. I. (2020). Competency-based education in undergraduate clinical prosthodontics: A paradigm shift in training. The Journal of Competency-Based Education, e01220.

[3] Ananiev, B. G. (2008). Personality, the subject of activity and individuality. M.: Direct-Media, 134.

[4] Arkhipova, M. Y., \& Kuchmaeva, O. V. (2018). Social demand for Russians for innovation (according to a sample survey). Economic and Social Changes: Facts, Trends, 
Forecast, 11(2), 69-83.

[5] Bakhru, S. A., \& Mehta, R. P. (2020). Assignment and Project Activity Based Learning Systems as an Alternative to Continuous Internal Assessment. Procedia Computer Science, 172, 397-405.

[6] Dorofeeva, A. A., \& Nyurenberger, L. B. (2019). Trends in digitalization of education and training for industry 4.0 in the Russian Federation. IOP Conference Series: Materials Science and Engineering, 537(4), 042070.

[7] Eliseeva, E., Makarova, G., Feschenko, V., Komarova, S., Kazimirova, N., \& Sevryukova, S. (2016). Features of Preparation of Creative Professionals in the Educational Environment of the Modern University. International Review of Management and Marketing, 6(1S).

[8] Fahrutdinova, R. A., Fahrutdinov, R. R., \& Konopatskaya, E. A. (2014). Formation of general cultural competencies of students in the educational space of the University. Life Science Journal, 11(6), 525-529.

[9] Gaddy, C. G., \& Ickes, B. W. (2002). Russia's virtual economy. Brookings Institution Press.

[10] Hache, E., Seck, G. S., Simoen, M., Bonnet, C., \& Carcanague, S. (2019). Critical raw materials and transportation sector electrification: A detailed bottom-up analysis in world transport. Applied Energy, 240, 6-25.

[11] Kanchana, S., Patchainayagi, S., \& Rajkumar, S. (2019). Empowering students to become effective learners through activity-based learning. Humanities \& Social Sciences Reviews, 7(5), 57-62.

[12] Karakozov, S. D., \& Ryzhova, N. I. (2019). Information and education systems in the context of digitalization of education. Журнал Сибирского Федерального Университета. Серия: Гуманитарные Науки, 12(9), $1635-1647$.

[13] Kesici, A., \& Tunç, N. F. (2018). Investigating the Digital Addiction Level of the University Students According to Their Purposes for Using Digital Tools. Universal Journal of Educational Research, 6(2), 235-241.

[14] Kunanbayeva, S. S. (2016). Educational Paradigm: Implementation of the Competence-Based Approach to the Higher School System. International Journal of Environmental and Science Education, 11(18), 1269912710.

[15] Laurila, J. (2003). Transit transport between the European Union and Russia in light of Russian geopolitics and economics. Emerging Markets Finance and Trade, 39(5), $27-57$.

[16] Levine, E., \& Patrick, S. (2019). What Is Competency-Based Education? An Updated Definition. Aurora Institute.

[17] Machekhina, O. N. (2017). Digitalization of education as a trend of its modernization and reforming. Revista Espacios, $38(40)$.
[18] Makarova, I., Shubenkova, K., Bagateeva, A., \& Pashkevich, A. (2018). Digitalization of education as a new destination of e-learning. 2018 International Symposium ELMAR, 31-34.

[19] Marusynets, M., Vakolia, Z., \& Perepeliuk, I. (2019). The moral education of children and youth from a pedagogical retrospective. International Journal of Social and Educational Innovation (IJSEIro), 30-39.

[20] Medvedev, D. A. (2018). Russia-2024: the strategy of social and economic development. VOPROSY ECONOMIKI, 10

[21] Mertala, P. (2020). Paradoxes of participation in the digitalization of education: a narrative account. Learning, Media and Technology, 45(2), 179-192.

[22] Orekhova, Y. Y., Grebenkina, L. K., Martishina, N. V., \& Badelina, M. V. (2019). Implementation of competency-based approach in interactive teaching of future Masters of Education. Revista ESPACIOS, 40(29).

[23] Plotnikova, E. (2019). Digitalization of education in the leading universities of Saint Petersburg. IOP Conference Series: Materials Science and Engineering, 497(1), 012047.

[24] Popkova, E. G., \& Sergi, B. S. (2020). Human capital and AI in industry 4.0. Convergence and divergence in social entrepreneurship in Russia. Journal of Intellectual Capital.

[25] Prapinpongsakorn, S. (2020). Application of Activity-Based Blended Learning Approach in Information Studies Education. Journal of Information Science, 38(3), 38-64.

[26] Romanovtseva, O. V. (2016). The competence approach in education. Contemporary Problems of Social Work, 2(4), 8.

[27] Sá, M. J., \& Serpa, S. (2020). COVID-19 and the promotion of digital competences in education. Universal Journal of Educational Research, 8(10), 4520-4528.

[28] Safuanov, R. M., Lekhmus, M. Y., \& Kolganov, E. A. (2019). Digitalization of the education system. Vestnik USNTU. Science, Education, Economics. Series: Economics[«Tsifrovizatsiya Sistemy Obrazovaniya», Vestnik UGNTU. Nauka, Obrazovaniye, Ekonomika. Seriya: Ekonomika], 2, 28

[29] Sagers, M. J., Kryukov, V. A., \& Shmat, V. V. (1995). Resource rent from the oil and gas sector and the Russian Economy. Post-Soviet Geography, 36(7), 389-425.

[30] Sullivan, S. C., \& Downey, J. A. (2015). Shifting educational paradigms: From traditional to competency-based education for diverse learners. American Secondary Education, 43(3).

[31] Suydam, M. N., \& Higgins, J. L. (1977). Activity-based learning in elementary school mathematics: Recommendati ons from research.

[32] Zubkova, Ma., Iu, F. N., Baranova, En., Il, A. L., Pirozhkova, Ao., \& Bubenchikova, Av. (2019). Approaches to the future engineers foreign communicative culture formation. Humanities \& Social Sciences Reviews, 7(4), 781-786. 